\title{
Small Peptides Compound Isolated from Agkistrodon with Antiarthritic Effect in Collagen-Induced Arthritis Rats
}

\author{
Lijun Mei, ${ }^{1}$ Chen Lin $\mathbb{D}^{1},{ }^{1}$ Shanshan Lei, ${ }^{2}$ Li Xu ${ }^{\mathbb{D}},{ }^{1}$ and Yong-Sheng Fan $\mathbb{D}^{1}$ \\ ${ }^{1}$ Zhejiang Chinese Medical University, Hangzhou, Zhejiang 310053, China \\ ${ }^{2}$ Zhejiang University of Technology, Hangzhou, Zhejiang 310014, China \\ Correspondence should be addressed to Li Xu; xulihhb@163.com and Yong-Sheng Fan; applezjtcm@126.com
}

Received 30 November 2017; Revised 28 February 2018; Accepted 22 March 2018; Published 29 April 2018

Academic Editor: Antonella Fioravanti

Copyright (c) 2018 Lijun Mei et al. This is an open access article distributed under the Creative Commons Attribution License, which permits unrestricted use, distribution, and reproduction in any medium, provided the original work is properly cited.

\begin{abstract}
Agkistrodon in Chinese medicine has long been used as an effective treatment against rheumatoid arthritis (RA). The present research further investigated the effects of peptides extracted from the crude Agkistrodon on the RA rat model. Extracted peptides were separated by parameter-optimized ion-exchange chromatography (IEC), peptide fractions were further analysed by MALDITOF/TOF MS, and nano-LC-MS/MS acquired mass spectra were further characterized using Mascot software, which ranks the best matches in the NCBI database. RT-PCR results in RAW264.7 cells indicated that Agkistrodon peptide components had inhibitory effects against inflammatory cytokines. The therapeutic efficacy of Agkistrodon peptides was evaluated on the Wistar rats with collagen-induced arthritis. Symptom relief and reduced cartilage destruction and bone erosion were observed, which can be explained by the direct suppression of inflammatory cytokines in the joints. Agkistrodon peptides downregulate the expression of TNF- $\alpha$, IL- $1 \beta$, and IL- 6 , which may alleviate cartilage destruction and bone erosion, thus relieving symptoms of RA.
\end{abstract}

\section{Introduction}

Rheumatoid arthritis (RA) is a chronic inflammatory disorder characterized by progressive destruction of patients' joints caused by cellular infiltration and proliferation of synovium [1]. Proinflammatory cytokines including TNF$\alpha$, IL- $1 \beta$, and IL- 6 are overproduced in the rheumatoid joints and are critical mediators in the pathogenesis of RA, promoting leukocytes, and osteoclasts activation, driving destruction of bone and cartilage [2]. Inhibiting of proinflammatory cytokines has been shown to improve disease symptomatology and outcome in rodent arthritis models and human clinical trials $[3,4]$.

The prognosis of RA so far is discouraging, given that common treatments including disease-modifying antirheumatic drugs (DMARDs) and nonsteroid anti-inflammatory drugs (NSAIDs) partially relieve patients' symptoms with limited and short-term effectiveness [5, 6], and prolonged usage might cause serious adverse effects such as leukopenia, elevated transaminases, and infection [7-9]. On the other hand, it is increasingly acknowledged that natural products with antiarthritic effects might be a good choice for potent and safe treatment of RA [10]. Insects as natural product resources have since ancient times been used for antiarthritic therapy [11]. Successful isolation of bioactive molecule from secretions, excretions, and bodies of insects further encourages the in-depth exploration of their functional mechanisms [12].

A wide range of small peptide toxins have been separated from venoms and larvae. Bioactive peptides inhibit synovial angiogenesis by binding to the vasculature endothelial cells [13] or suppressing immune response by inhibiting induction of T-cell mediated inflammation [14]. Recent studies searching from snake venoms have successfully identified antiinflammatory and antiarthritic activities components and further demonstrated that their beneficial effects might be attributed to the inhibition of NF- $\kappa \mathrm{B}$ pathway and suppression of T-cell/FLSs proliferation [15-17]. Preclinical models of peptide immunotherapy have demonstrated efficacy in autoimmunity, shedding light on the potential as pharmaceutical agents $[18,19]$.

In the present study, peptides isolated from the crude medicine of snake Agkistrodon acutus were analysed for their potency/efficacy on/against arthritis. The dried powder of 
Agkistrodon acutus has been successfully applied in Chinese medicine as an antiarthritic drug, and previous work explored and determined the optimal treatment dosage [20]. Peptides' cytotoxicity and cytokine-inhibiting effects were tested and affirmed by both in vitro and in vivo experiments. Possible mechanism in association with the cytokineinhibiting effect was discussed.

\section{Materials and Methods}

2.1. Animals and Cells. Female Wistar rats $(n=30,6-7$ weeks of age) were obtained from the Laboratory Animal Research Center of Zhejiang Chinese Medical University (China; rodent license number SYXK (Zhe) 2003-0184). After acclimatization for 7 days, four rats were housed in each Individual Ventilation Cage (IVC) and were maintained in accordance with national standards (Laboratory Animal Requirements of Environment and Housing Facilities, GB 14925-2001). Six rats were randomized into a normal control group and all others were used for the CIA model. RAW264.7 cells were purchased from the Shanghai Institutes for Biological Sciences, Chinese Academy of Sciences.

2.2. Reagents. The Agkistrodon for the Agkistrodon powder and the Agkistrodon peptide preparation was purchased from the Chinese Herbal Medicine Co., Ltd., of Zhejiang Chinese Medical University (Hangzhou, China). Glycoside of Tripterygium wilfordii (number 1507101B) was purchased from Zhejiang Deende Pharmaceutical Co., Ltd., China. Foetal bovine serum (FBS, number 10099141) was purchased from Gibco Life Technologies., Inc., USA, and highglucose Dulbecco's modified Eagle's medium (DMEM) was purchased from Hangzhou Sijiqing Biological Engineering Materials Co., Ltd., China. The Cell Titer 96 AQueous One Solution Cell Proliferation Assay (MTS, number G3581) and lipopolysaccharide (LPS, number L2880) were purchased from Sigma, USA. TRIzol reagent (number 9109) and Prime Script RT Master Mix (number RR036A) were purchased from TaKaRa, Japan. SYBR-Green Supermix (number 1708882AP) was purchased from Bio-Rad, USA. The specific primers for the target genes and GAPDH were synthesized by and purchased from Shanghai Shenggong Co., China. Incomplete Freund's adjuvant (IFA, number SLBK3881V) was purchased from Sigma, USA. Bovine type II collagen (CII, number 20021) and the enzyme-linked immunoassay (ELISA) kit (number 2042) were purchased from Chondrex, USA. The TNF- $\alpha$ polyclonal antibody (number YT4689) and IL- $\beta$ polyclonal antibody (number YT5201) were purchased from ImmunoWay, USA. The IL-6 polyclonal antibody (number BS6419) was purchased from Bioworld, USA.

2.3. Peptide Separation. Extraction of crude peptides was processed following instructions of the boiling method with dilute ethanol recorded in the Chinese Pharmacopeia (2010 edition). Briefly, 10 grams of crude Agkistrodon medicine was powdered and sifted through a $149 \mu \mathrm{m}$ mesh filter and then was further dried for $30 \mathrm{~min}$ to remove any additional water. The powder was then soaked in $50 \%$ dilute ethanol, with its weight/volume percentage concentration to be $10 \%$. The total crude peptides were heat reflux extracted for $1 \mathrm{~h}$ and then after cooling to room temperature, the solution was centrifuged at $10000 \times \mathrm{g}$ for $20 \mathrm{~min}$. Supernatants were collected and tested for protein/peptide concentration and then lyophilized at $-56^{\circ} \mathrm{C}$ and stored for further tests.

Lyophilized crude peptides, 1.8 grams, were measured and dissolved in pure water. Ion-exchange chromatography was used for separation. An XK 26/20 column was packed with Resins purchased from GE, USA, and separation was performed with a $0-0.5 \mathrm{M} \mathrm{NaCl}$ gradient and monitored at a $215 \mathrm{~nm}$ wavelength. Eluted peptide peaks were collected and desalted by dialysis with a $500 \mathrm{Da}$ cutoff before being lyophilized and further analysed by an AB SCIEX 5800 MALDI-TOF/TOF mass spectrometer (AB Sciex, Canada) in linear positive mode. Mass spectra were analysed using Data Explorer 4.5 software (Perspective Bio Systems). Spectra were acquired over the mass range of $600-4,000 \mathrm{Da}$ using 50 laser shots in the positive ion mode at a laser power of $25 \%$.

2.4. MALDI-TOF Analysis. The molecular mass of lyophilized peptides was analysed by MALDI-TOF/TOF on an AB SCIEX 5800 Proteomics Analyser (AB Sciex, Canada). Samples were mixed thoroughly at a ratio of $1: 1(\mathrm{v} / \mathrm{v})$ with a saturated matrix solution ( $\alpha$-cyano-4-hydroxycinnamic acid, $5 \mathrm{mg} / \mathrm{mL}$ prepared in $50 \%$ acetonitrile $/ 0.1 \%$ trifluoroacetic acid), and $0.5 \mu \mathrm{l}$ of the mixture was spotted onto a target plate. The mixture was fully dried before analysis. The instrument was calibrated externally using a mixture of peptide standards obtained from Sigma-Aldrich (MS-Cal1). Positive ion (MH+) spectra were acquired in the linear MALDI-TOF mode. The $\mathrm{m} / \mathrm{z}$ signals were recorded between 1,000 and 10,000 $\mathrm{Da}$ for peptide detection.

2.5. LC-MS/MS Analysis. To explore and identify speciesspecific peptides, LC/MS/MS analysis was performed. The collected peptide sample was analysed by a Thermo Q Exactive mass spectrometer (Thermo, San Jose, CA) with a nanospray ion source. The lyophilized peptides were dissolved in $\mathrm{FA}-\mathrm{H}_{2} \mathrm{O}(0.1: 99.9, \mathrm{v} / \mathrm{v})$ and preconcentrated on a $2 \mathrm{~cm}$ trap column $(100 \mu \mathrm{m}$ i.d.) that was packed with $\mathrm{C} 18 \mathrm{AQ}$ beads $(5 \mu \mathrm{m}, 120 \AA$, Daison, Osaka, Japan). A second $10 \mathrm{~cm}$ capillary analysis column ( $75 \mu \mathrm{m}$ i.d.) was packed with $\mathrm{C} 18$ $\mathrm{AQ}$ beads ( $3 \mu \mathrm{m}, 120 \AA$, Daison, Osaka, Japan) and was used to separate the peptides. Eluting buffers were $99.9 \% \mathrm{H}_{2} \mathrm{O}$ with $0.1 \%$ FA (buffer A) and $84 \%$ ACN with $0.1 \%$ FA (buffer B). The separation system was equilibrated initially with buffer $A$, and a linear elution gradient (at flow rate of $320 \mathrm{nil} / \mathrm{min}$ ) was performed, from 4 to $50 \%$ buffer B (formic acid-acetonitrile, $0.1: 99.9$ ) in $20 \mathrm{~min}$ and from $50 \%$ to $100 \%$ buffer B (FAacetonitrile, $0.1: 99.9)$ in $5 \mathrm{~min}$, and then held at $100 \%$ buffer $\mathrm{B}$ for another $5 \mathrm{~min}$. The MS/MS spectra were obtained in collision-induced dissociation (CID) mode, and a full mass scan was acquired from $\mathrm{m} / \mathrm{z} 400$ to 2000 with a resolution of 70,000 . The 10 most intense ions with a charge above 2 and intensity threshold higher than 104 were selected for MS/MS. Dynamic exclusion was set at $30 \mathrm{~s}$.

2.6. Data Analysis. Raw mass spectrometry data were compared with that of the Squamata in the NCBI database using 
TABLE 1: Primers for the target genes used in RT-PCR.

\begin{tabular}{|c|c|c|}
\hline Target gene & Primer & Length of target fragment (bp) \\
\hline \multirow{2}{*}{ TNF- $\alpha$} & $5^{\prime}$-CCACATCTCCCTCCAGAAAAGA -3' (F) & \multirow{2}{*}{768} \\
\hline & $5^{\prime}$-GCTGGGTAGAGAATGGATGAAC - $3^{\prime}(\mathrm{R})$ & \\
\hline \multirow{2}{*}{ IL- $1 \beta$} & $5^{\prime}$-GCTTCAGGCAGGCAGTAT - $3^{\prime}(\mathrm{F})$ & \multirow{2}{*}{472} \\
\hline & $5^{\prime}$-ACAAACCGCTTTTCCATCT - $3^{\prime}(\mathrm{R})$ & \\
\hline \multirow{2}{*}{ IL-6 } & $5^{\prime}$-GAAATCGTGGAAATGAG -3' (F) & \multirow{2}{*}{455} \\
\hline & $5^{\prime}$-TAGGTTTGCCGAGTAGA - $3^{\prime}(\mathrm{R})$ & \\
\hline \multirow{2}{*}{ GAPDH } & $5^{\prime}$-TGCACCACCAACTGCTTAG - $3^{\prime}(\mathrm{F})$ & \multirow{2}{*}{177} \\
\hline & $5^{\prime}$-GGATGCAGGGATGATGTTC $-3^{\prime}$ (R) & \\
\hline
\end{tabular}

\begin{tabular}{|c|c|c|c|c|c|c|}
\hline $\begin{array}{l}\text { Primary } \\
\text { immunization }\end{array}$ & Booster & \multicolumn{4}{|c|}{ Treatment } & \\
\hline 1 & 7 & 14 & 17 & 23 & 29 & 35 (Days) \\
\hline
\end{tabular}

FIGURE 1: Scheme of animal experiment protocol. From day 14, rats with CIA were treated with Glycoside of Tripterygium wilfordii, Agkistrodon powder, and Agkistrodon peptides.

the Mascot search algorithm (version 2.2), which ranks the best fit peptide matches based on a cumulative protein score of the unique peptides identified.

The criteria used for the Mascot search are as follows: trypsin was used as the protease with a maximum of 1 missed cleavage allowed; the protein oxidation of methionine was fixed as a dynamic modification whereas the carbamidomethyl of cysteine was retained as a static modification; and the protein list was further filtered by applying a false discovery rate cutoff of $1 \%$ at the protein level. The data were filtered for ion scores of at least 60 . For each file, an ion score $>20$ indicated identity or extensive homology with $P<0.05$.

2.7. Cell Culture and Cytotoxicity Assay. The RAW264.7 cells were cultured in high-glucose DMEM with $10 \% \mathrm{FBS}$ in a $37^{\circ} \mathrm{C}$ incubator with $5 \% \mathrm{CO}_{2}$. The viability of RAW264.7 cells was evaluated with the MTS assay. The cells were seeded in 96well plates at a density of $10 \times 10^{4}$ cells/well for $24 \mathrm{~h}$ and then treated with various concentrations of separated peptides $(0.1$, $1,10,100$, or $1000 \mu \mathrm{g} / \mathrm{mL}$ ) for $24 \mathrm{~h}$. Optical density (OD) was measured at $450 \mathrm{~nm}$ using a Multiskan Spectrum Microplate Spectrophotometer (Bio-Rad, California, USA). Cell viability was expressed as a percentage of the control.

2.8. RNA Extraction and Real-Time Polymerase Chain Reaction (RT-PCR) Analysis. The RAW264.7 cells were cultured in 6-well plates at a density of $10 \times 10^{4}$ cells $/ \mathrm{mL}$ for $24 \mathrm{~h}$. Following pretreatment with LPS $(10 \mu \mathrm{g} / \mathrm{mL})$ for $4 \mathrm{~h}$, the cells were treated with different concentrations of Agkistrodon peptides $(1,10$, or $100 \mu \mathrm{g} / \mathrm{mL})$ for $24 \mathrm{~h}$.

Total RNA was extracted using TRIzol reagent. Realtime PCR was performed using SYBR-Green Supermix on a Bio-Rad iQ5 Real-time PCR system (Bio-Rad, California, USA). The mouse primer sequences were used as described in Table 1. Data were calculated using the formula $2^{-\Delta \Delta \mathrm{Ct}}$ and all values were normalized to the level of GAPDH.
2.9. Induction of Collagen-Induced Arthritis (CIA). CII was dissolved in $100 \mathrm{mM}$ acetic acid at the concentration of $4 \mathrm{mg} / \mathrm{mL}$ by stirring overnight at $4^{\circ} \mathrm{C}$. Dissolved CII was emulsified with an equal volume of incomplete Freund's adjuvant (IFA) on ice using a T-branch pipe and two syringes to make the final concentration of $2 \mathrm{mg} / \mathrm{mL}$ CII/IFA emulsion. For the primary immunization, CII/IFA emulsion was injected subcutaneously at the base of the rat tail, as the first site, and on the back, as the second site, totalling $200 \mu \mathrm{l}$ of emulsion containing $400 \mu \mathrm{g}$ of CII. A booster injection was given on day 7 after the initial immunization with $100 \mu$ l of the emulsion containing $200 \mu \mathrm{g}$ of CII. Visually apparent arthritis with swollen joints appeared approximately 11-13 days after the first injection.

2.10. Animal Grouping and Treatment. After the joints swelling was successfully established in at least one paw, the rats were randomized into groups, with the mean of their hind paw volumes and arthritis scores in each group approximately equal. Rats with CIA were randomly divided into 4 groups: Glycoside of Tripterygium wilfordii (GTW, $0.72 \mathrm{mg} / \mathrm{kg}$ body weight, administered by gastric gavage daily), Agkistrodon powder (APO, $580 \mathrm{mg} / \mathrm{kg}$ body weight, administered by gastric gavage daily), Agkistrodon peptides (APE, $4 \mathrm{mg} / \mathrm{kg}$ body weight, administered by intraperitoneal injection daily), and the CIA model group (Figure 1). In addition, the normal control group received nothing. In this study, there were six mice per group and a total of 5 groups.

2.11. Evaluation of Paw Swelling Degree. The paw swelling degree was determined by measuring the change in the hind paw volume $(\mathrm{mL})$ with a plethysmometer (type: YLS-7C, Yanyi Technology Development Co., Ltd., Jinan, China). The paw swelling rate (\%) was expressed as increased multiples of the hind paw volume by subtracting the paw volume before the primary immunization. 
TABLE 2: Separated peptide fractions of Agkistrodon identified by Mascot.

\begin{tabular}{lcccccc}
\hline Number & Sequence & MW $(\mathrm{MH}+)$ & Diff $(\mathrm{MH}+)$ & PI & Score & $P$ value \\
\hline 1 & R.GPPGSSGSPGK.D & 927.45305 & -0.00007 & 8.75 & 92.7 & $6.08 E-08$ \\
2 & K.GDAGPAGPK.G & 769.38389 & -0.00022 & 5.84 & 84.55 & $4.16 E-07$ \\
3 & R.GFSGLDGAK.G & 851.42576 & 0.00022 & 5.84 & 75.76 & $4.13 E-06$ \\
4 & R.DGAAGPK.G & 615.30966 & -0.00008 & 5.84 & 66.96 & $1.37 E-05$ \\
5 & K.GEPGDAGAK.G & 801.37372 & 0.00048 & 4.37 & 60.84 & $5.36 E-05$ \\
\hline
\end{tabular}

2.12. Estimation of Arthritis Indexes. The development of arthritis in the hind paws of rats was evaluated before treatment and on days $14,17,23,29$, and 35 by using a qualitative scoring system: 0 , normal; 1 , mild, but definite redness and swelling of the ankle or wrist or the apparent redness and swelling are limited to individual digits; 2 , moderate redness and swelling of the ankle; 3 , severe redness and swelling of the entire paw including the digits; and 4, maximally inflamed limb involving multiple joints.

2.13. Determination of Type II Collagen IgG Antibodies. IgG antibodies against type II collagen in serum was assessed with ELISA kits. According to the manufacturer's protocol, serum samples from arthritic rats were centrifuged at 10,000 rpm for 3 minutes and diluted with sample dilution buffer from $1: 20,000$ to $1: 80,000$. The OD values were read at $490 \mathrm{~nm}$ using a Multiskan Spectrum Microplate Spectrophotometer (Bio-Rad, California, USA) and expressed as units per millilitre.

2.14. Radiographic Examination. At the end of the study (day 35 ), the hind limbs were collected for radiographic evaluation. X-ray radiography of the ankle joint was performed using an in vivo Imaging System FX (Carestream Health, Rochester, USA) with a $35 \mathrm{~kW}$ exposure for $2 \mathrm{~min}$. The three-dimensional reconstruction and images were obtained by using high-resolution in vivo X-ray microtomography (Bruker, Germany).

2.15. Histologic Assessments. At the end of the study (day 35), the hind limbs were preserved in $10 \%$ neutral buffered formalin fixative and then placed in decalcifying solution (a mixture comprising formic acid, hydrochloric acid, and distilled water) for 50 days (decalcifying solution was exchanged every 5 days). After that, all ankles were longitudinally trimmed, embedded in paraffin, sectioned at $5 \mu \mathrm{m}$, and stained with haematoxylin and eosin $(\mathrm{H} \& \mathrm{E})$, safranin $\mathrm{O}$, and toluidine blue.

2.16. Immunohistochemical Analysis. For immunohistochemistry, sections were prepared from the same preparations used for H\&E staining. The sections were incubated with specific antibodies for rat TNF- $\alpha$, IL-1 $\beta$, and IL-6. Images were observed with light microscopy (Nikon, Tokyo, Japan) and representative images were revealed.

2.17. Statistical Analysis. Data were expressed as the mean \pm SEM or mean \pm SD. For comparisons among groups, a one-way analysis of variance (ANOVA) followed by a
Games-Howell test was performed to test significant differences. All data were analysed using SPSS 17.0. $P<0.05$ was considered to be statistically significant.

\section{Results}

3.1. Agkistrodon Peptides Compound Isolation and Identification. Following instructions of the Chinese Pharmacopeia (2010 edition), crude peptides were extracted and were further separated by taking advantage of ion-exchange chromatography. Initial separation using a $0-100 \%$ linear gradient of $\mathrm{NaCl}$ was unsuccessful (data not shown), which might be attributed to the existence of components not responsive to the $\mathrm{NaCl}$ gradient. The separation protocol was therefore modified by increasing the $\mathrm{NaCl}$ to $0.5 \mathrm{M}$ after the elution of detected peaks of $\mathrm{NaCl}$-unresponsive. An elution peak responding to the increased $\mathrm{NaCl}$ was observed, and repeat tests performed demonstrated similar results (Figure 3(a)).

The $\mathrm{NaCl}$ responsive eluate was collected and further dialyzed for mass determination by MALDI-TOF/MS. Two peaks $(\mathrm{m} / z 1022.33$ and 1097.87$)$ over $50 \%$ intensity were observed within the mass range from $1,000 \mathrm{Da}$ to $10,000 \mathrm{Da}$, indicating small molecular weight peptides 10 amino acids long (Figure 3(b)).

Liquid chromatography tandem mass spectrometry (LCMS/MS) was used to further identify the peptides. Output of the high-resolution MS/MS spectra, generated by the fragmentation of the precursor, with corresponding intensities was searched against the NCBI protein database of the taxonomy of Squamata (158856 entries, downloaded December 2016) using the Mascot search engine (version 2.2) (Table 2), revealing that the signals at $m / z=927.4531$ $[\mathrm{M}+\mathrm{H}+]$ and $m / z=769.38389, \mathrm{~m} / z=851.42576, \mathrm{~m} / z=$ 615.30966 , and $m / z=801.37372[\mathrm{M}+\mathrm{H}+]+$ corresponded to the single-protonated fragments of collagen alpha-1(I) chain from Ophiophagus hannah.

3.2. Effect of Agkistrodon Peptides Compound on Cell Viability and the $m R N A$ Expression of TNF- $\alpha, I L-1 \beta$, and $I L-$ 6 in RAW264.7 Cells. To investigate the cytotoxicity of Agkistrodon peptides, the viability of RAW264.7 cells was evaluated by using the MTS assay (Figure 4(a)). Treatment with Agkistrodon peptides $(0.1-100 \mu \mathrm{g} / \mathrm{mL})$ did not have a marked cytotoxic effect on the RAW264.7 cells. Furthermore, the anti-inflammatory effect was evaluated by stimulating the RAW264.7 cells with LPS. The stimulation of LPS promoted the expression of inflammatory cytokines at the mRNA level in RAW264.7 cells. However, treatment with Agkistrodon peptides suppressed the mRNA expression 


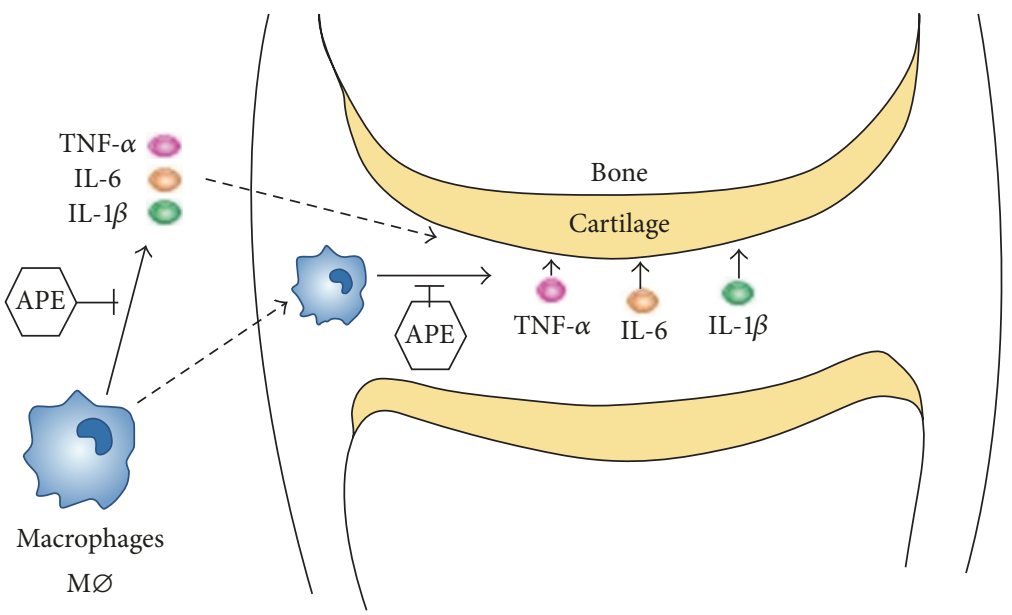

FIgURE 2: A schematic diagram of the effects and the principle molecular mechanisms of APE on Rheumatoid arthritis. APE reduces the recruitment of macrophages and thus downregulates the production of TNF- $\alpha$, IL-6, and IL- $1 \beta$, which are mainly released by macrophages.

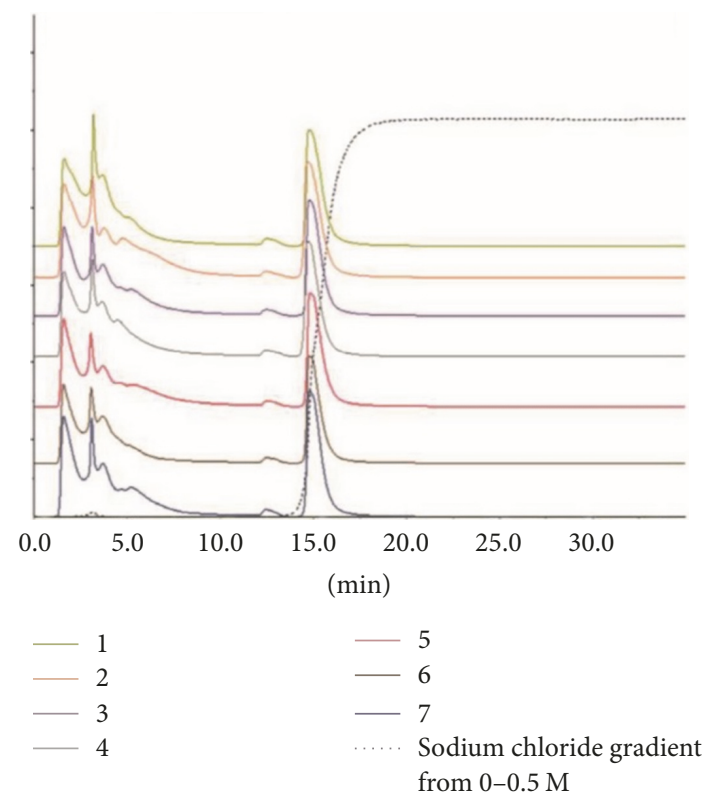

(a)

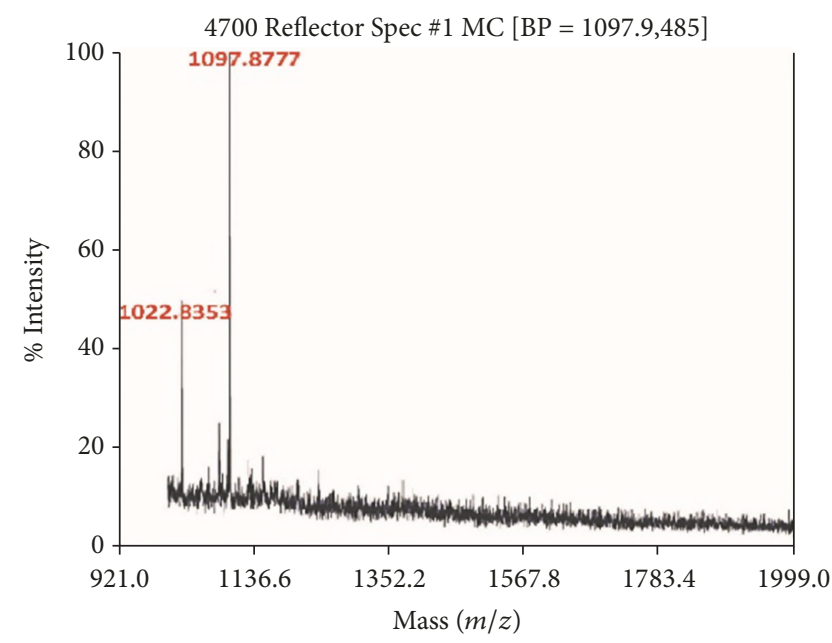

(b)

Figure 3: Agkistrodon peptides isolation and identification. (a) Seven repeats of fast separation of crude peptide mixture using ion-exchange chromatography. The dotted line refers to the sodium chloride gradient from 0 to $0.5 \mathrm{M}$. (b) Agkistrodon peptides identification by MALDI spectra.

of TNF- $\alpha$, IL- $1 \beta$, and IL- 6 in a dose-dependent manner (Figures $4(\mathrm{~b})-4(\mathrm{~d})$ ).

\subsection{Effect of Agkistrodon Peptides Compound on Paw Swelling} and Ankle Changes in Groups with CIA. The effect of Agkistrodon peptides on CIA was evaluation with the hind paw swelling rate and arthritis index. The degree of swelling in the normal control group showed no significant increase. Compared with the normal control group, the degree of swelling in all other groups showed significant increases (data not shown). At the end of the experiment, compared with the model group the degree of swelling in the rats of treated groups showed significant reductions $(P<0.05$ or $P<0.01$ ). The degree of swelling in rats from the APE group showed a continuously significant reduction at days 9 and 21 of treatment $(P<0.01)$. The strong antiinflammatory potency of the Chinese medicine Tripterygium wilfordii Hook (TWHF) has been verified [21-23], and the active component Tripterygium glycoside (GTW) [24-27] was used as the positive control in the present study.

Compared with those in either the GTW or APO group, those in the APE group had significantly reduced swelling. Additionally, there was no significant difference in paw volumes between the groups treated with GTW and APO (Figure 5(a)). 


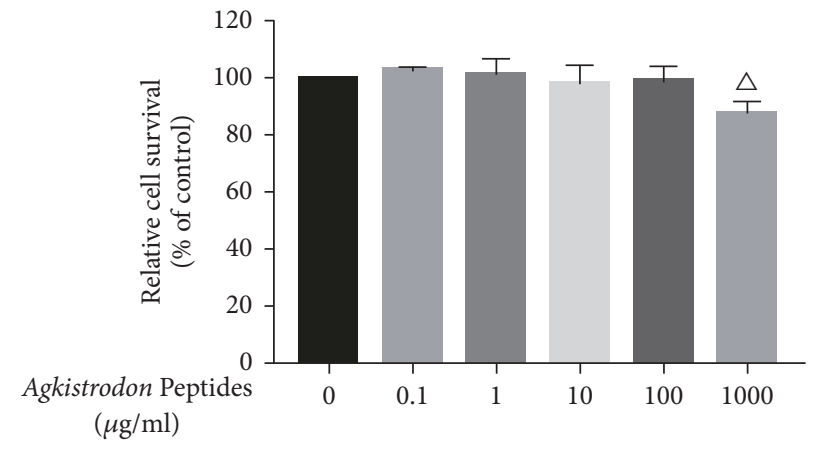

(a)

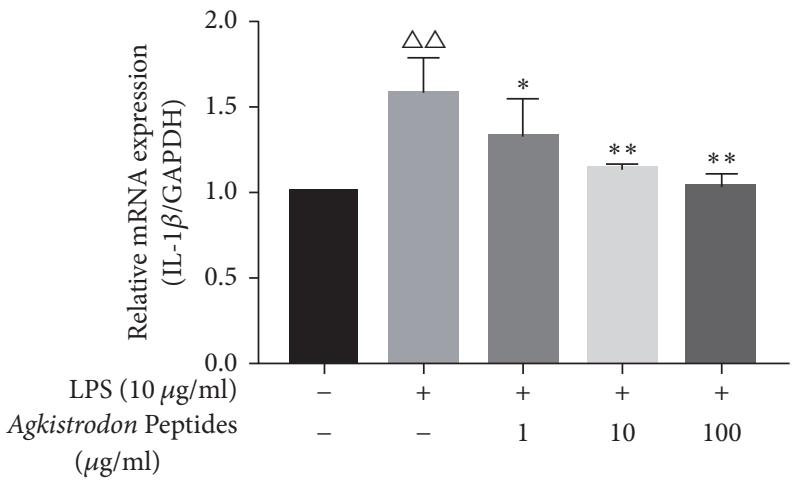

(c)

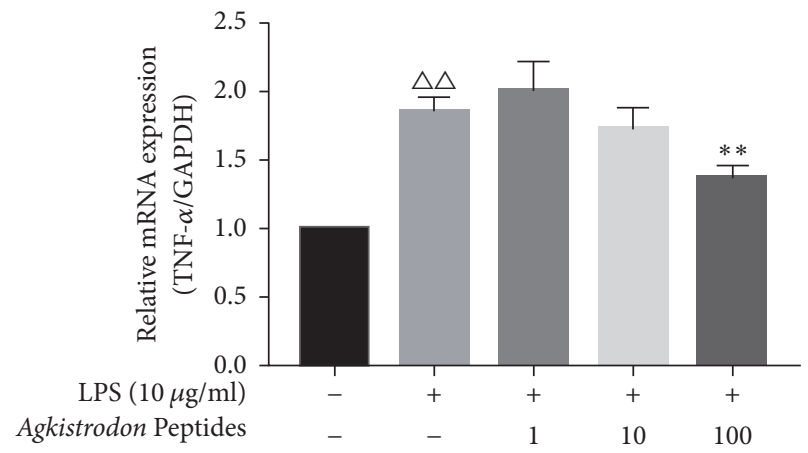

(b)

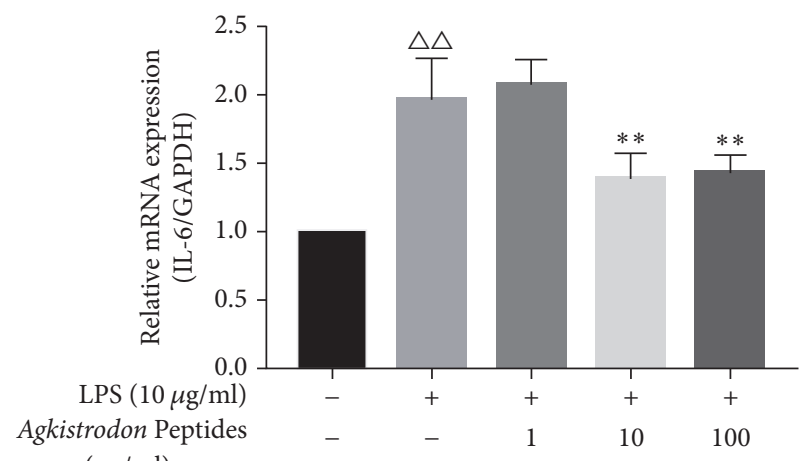

(d)

FIGURE 4: Effect of Agkistrodon peptides on the inflammatory cytokines mRNA expression in RAW264.7 cells. (a) The cytotoxic effect of Agkistrodon peptides on the viability of RAW264.7 cells. Cell viability was expressed as percentage of the control. Data were expressed as mean \pm SD. ${ }^{\triangle} P<0.05$ versus control. (b-d) The effect of Agkistrodon peptides on the mRNA expression levels of TNF- $\alpha$, IL-1 $\beta$, and IL-6 in LPS-stimulated RAW264.7 cells. Data were expressed as mean \pm SD. ${ }^{\triangle} P<0.05 ;{ }^{\triangle} P<0.01$ versus control. ${ }^{*} P<0.05$; ${ }^{* *} P<0.01$ versus the LPS-treated cells.

Visually apparent arthritis, with swollen joints in CIA rats, suggested that the CIA model was successfully established. At the end of the experiment, compared with the model group, all treated groups showed significant reductions $(P<0.05$ or $P<0.01)$ in clinical arthritis indexes. Compared with the model group, a significant reduction was observed in the APE group. In addition, the arthritis index of the APE group was significantly different compared to the APO group (Figure 4(b)).

Plain radiographic analysis revealed normal bone structure with smooth and intact sharp and bone substance in the normal rats. However, signs of arthritis with soft-tissue swelling, uniform joint space narrowing, and bone damage were observed in the joints of rats in the model group. Compared with the model group, the soft-tissue swelling in treated groups was minimal, and the bone damage was not severe. In addition, markedly alleviated plain radiographic changes were observed in the joints of rats in the APE group (Figure 6(a)). Similar results showing the severe joint destruction were obtained with the three-dimensional images. The images showed smooth bone surface and intact joint architecture in normal rats and notable bone destruction in the CIA model rats while the bone destruction was much less robust in the APE group, suggesting that Agkistrodon peptides can protect bone integrity induced by CIA (Figure 6(b)).
3.4. Anti-Inflammatory Effect of Agkistrodon Peptides on Type II Collagen Antibodies Expression in Serum and TNF- $\alpha$, IL$1 \beta$, and IL-6 Expression in Joints. The levels of anti-type II collagen IgG in treated groups was significantly reduced compared to the model group. The levels of anti-type II collagen IgG in the APE group were significantly lower than those in the GTW group. There was no significant difference between the APO and APE group (Figure 7).

Immunohistochemistry analysis revealed a higher expression of the inflammatory cytokines TNF- $\alpha$, IL-1 $\beta$, and IL- 6 in the model group compared to the normal group. However, the expression level of these three cytokines were markedly reduced in the APE group compared to the model group or to the other treated groups, suggesting that Agkistrodon peptides could suppress the expression of the inflammatory cytokines TNF- $\alpha$, IL- $1 \beta$, and IL- 6 under the arthritic conditions caused by CIA (Figures $8(\mathrm{a})-8(\mathrm{c})$ ).

3.5. Improvement Effect of Agkistrodon Peptides on Pathological of Joints. The sections stained with H\&E from the normal rats revealed that synovial cells on the surface of the ankle joints were well organized in the absence of inflammation. However, the images from rats in the model group revealed signs of severe arthritis with synovial hyperplasia, inflammatory cell infiltration, vascular pannus formation, and 


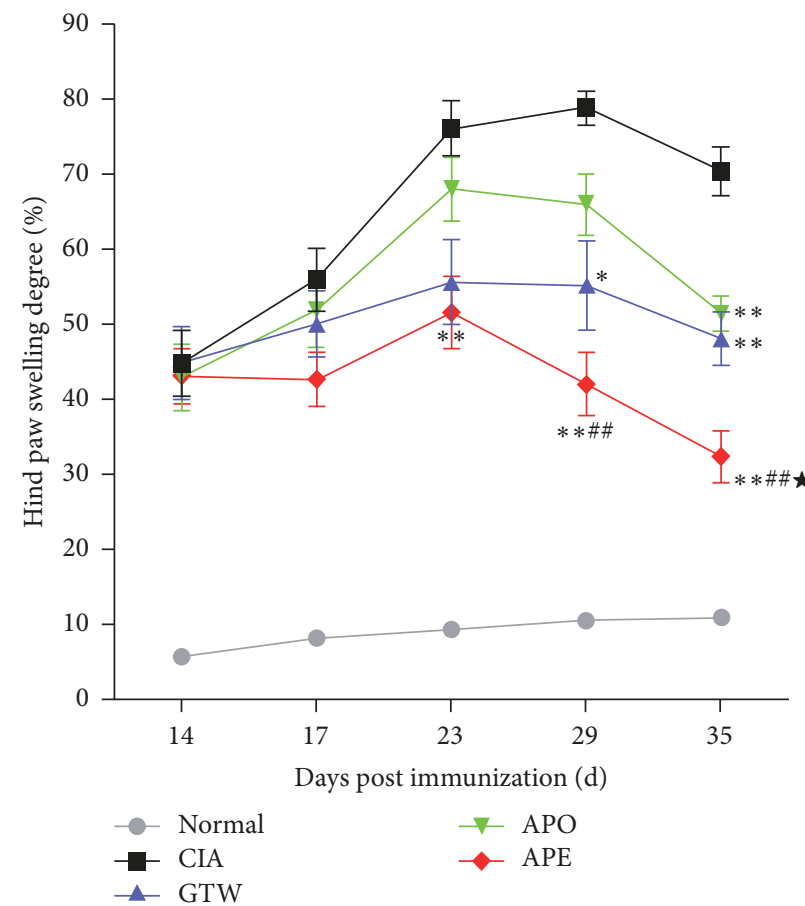

(a)

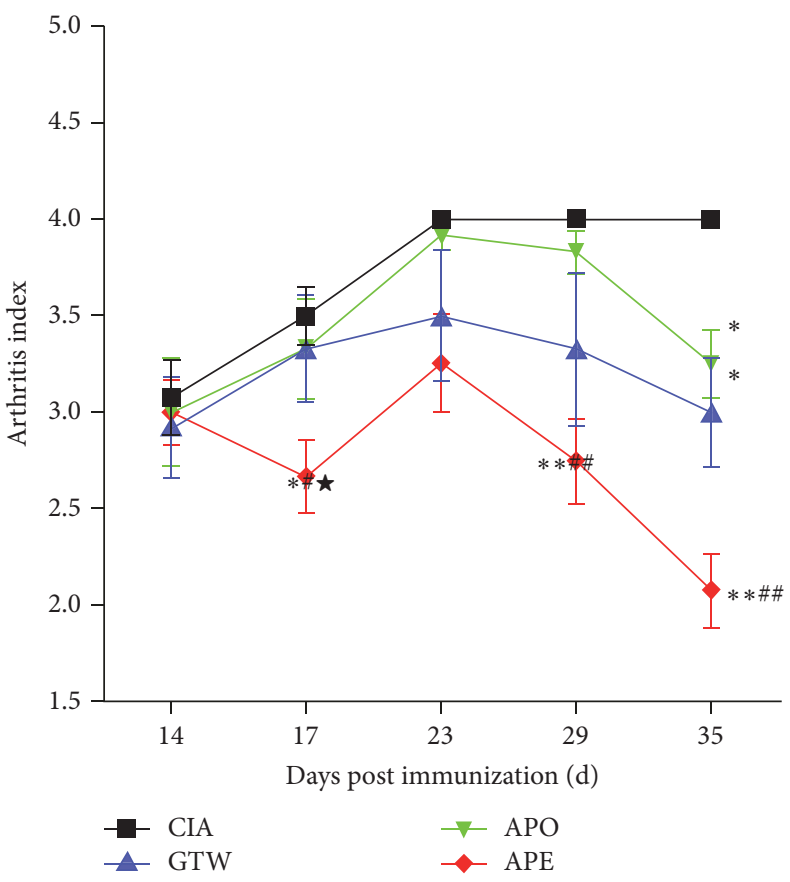

(b)

Figure 5: Paw swelling changes in different groups of CIA. (a) Paw swelling changes in different groups of CIA. Data were expressed as mean $\pm \operatorname{SEM}\left(n=12\right.$ hind paws). ${ }^{*} P<0.05 ;{ }^{* *} P<0.01$ versus the model group. ${ }^{\star} P<0.05$ versus the GTW group. ${ }^{\#} P<0.05 ;{ }^{\# \#} P<0.01$ versus the APE group. (b) Arthritis index changes in different groups of CIA. Data were expressed as mean \pm SEM $\left(n=12\right.$ hind paws). ${ }^{*} P<0.05$; ${ }^{* *} P<0.01$ versus the model group. ${ }^{\star} P<0.05$ versus the GTW group. ${ }^{\#} P<0.05$; ${ }^{\# \#} P<0.01$ versus the APO group.

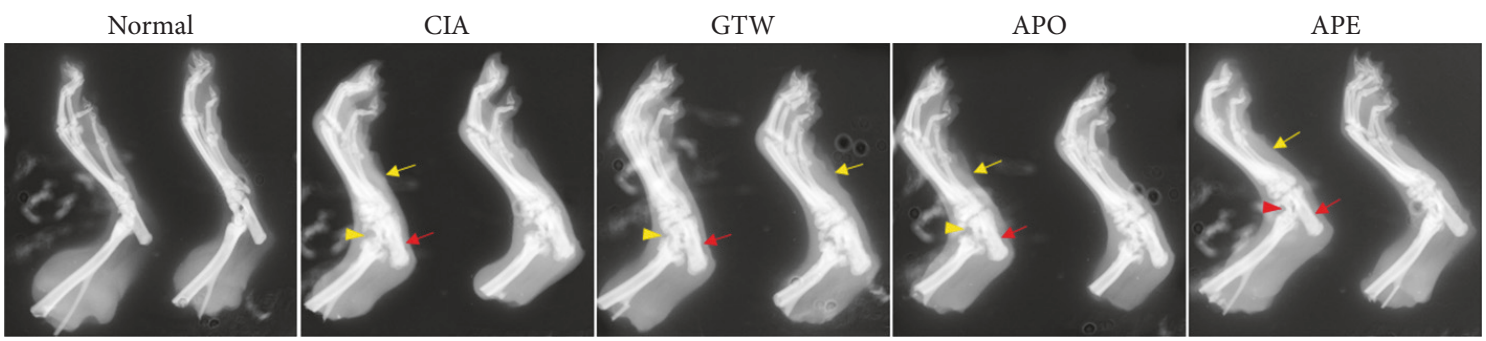

(a)
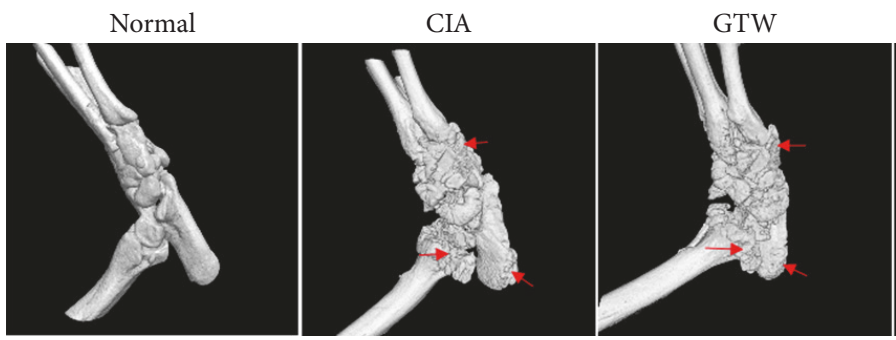

APO

APE

(b)

FIGURE 6: Plain radiographs and three-dimensional images of rats' joints. (a) The plain radiographs showed that soft-tissue swelling (yellow arrows), uniform joint space narrowing (triangles), and damaged bone substance (red arrows) were markedly alleviated in the joints of rats in the APE group. (b) The three-dimensional images showed that bone destruction (red arrows) was much less robust in the APE group compared with the model and other treated groups. 


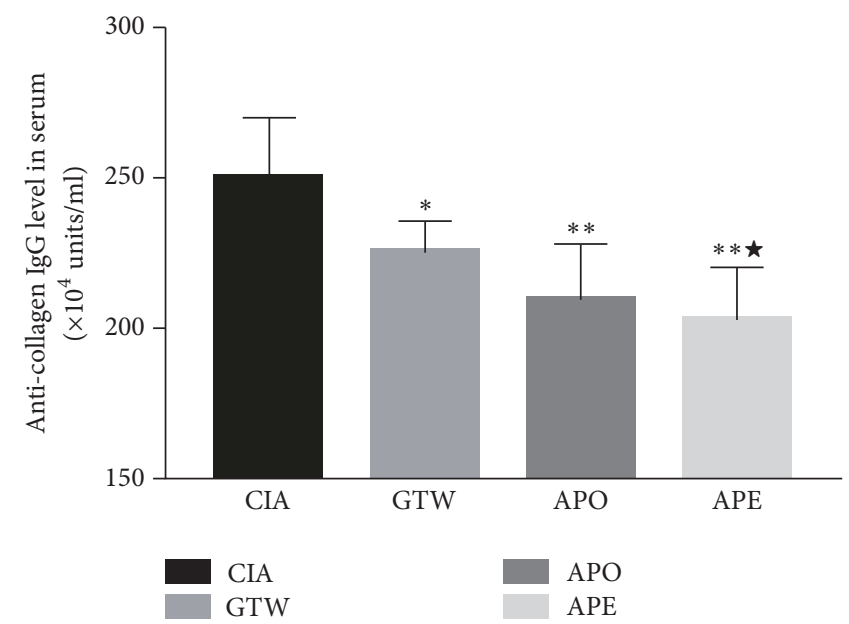

FIGURE 7: Expression of collagen type II IgG in serum in different groups of CIA. Data were expressed as mean \pm SD. ${ }^{*} P<0.05 ;{ }^{* *} P<0.01$ versus the model group. ${ }^{\star} P<0.05$ versus the GTW group.
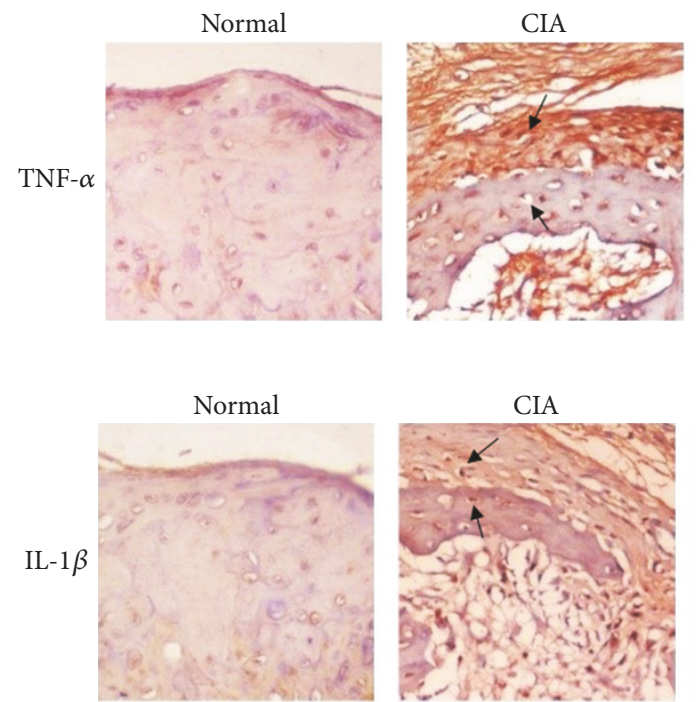

Normal

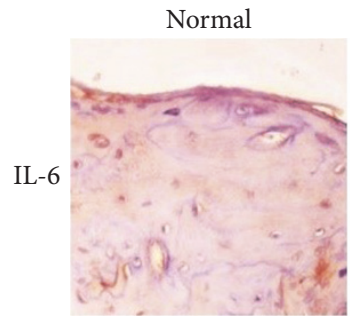

CIA

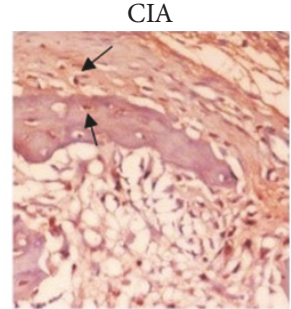

CIA

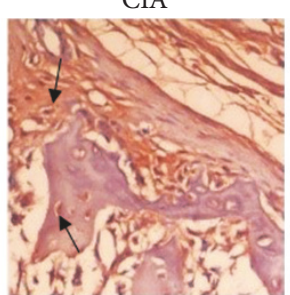

GTW

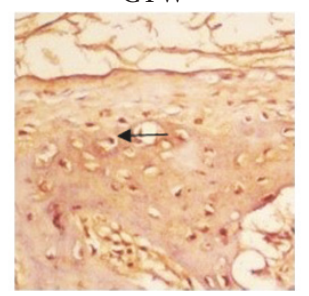

(a)

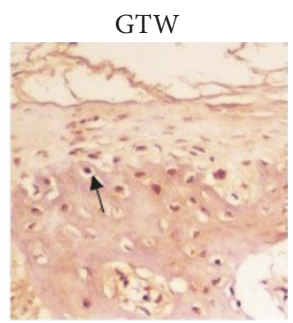

(b)

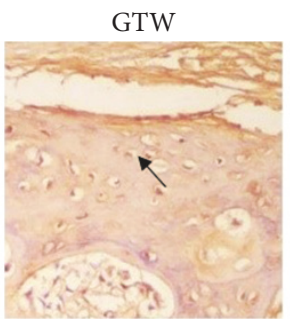

(c)
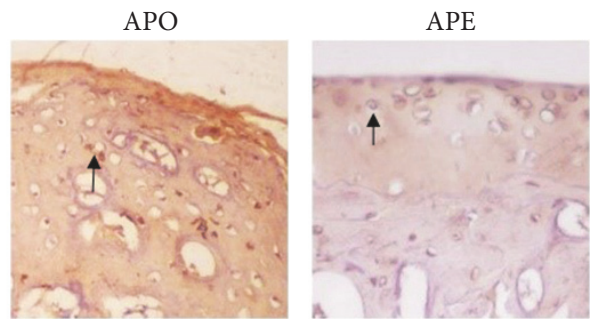

APO
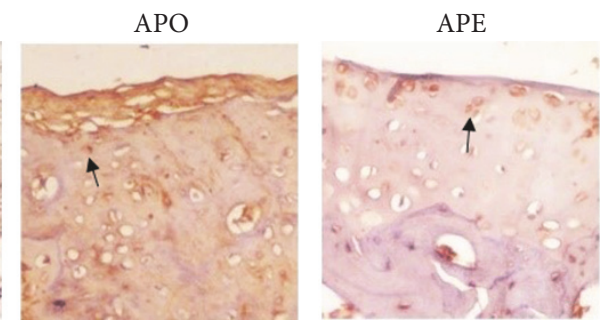

APO
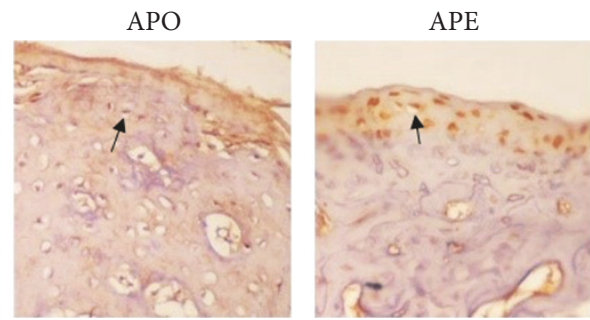

FIGURE 8: Immunohistochemistry analysis in different groups of CIA. (a) TNF- $\alpha$, (b) IL-1 $\beta$, and (c) IL-6 expression in joints (original magnification, $\times 200$ ). The expressions of TNF- $\alpha$, IL-1 $\beta$, and IL- 6 were decreased in joints of the treated groups compared with the model group. The arrows indicated locations of TNF- $\alpha$, IL- $1 \beta$, or IL- 6 .

cartilage destruction. The extent of synovial hyperplasia and inflammatory cell infiltration in the joint of rats in the treated groups was comparatively reduced. In contrast, intact articular cartilage and slight inflammatory cell infiltration were observed in the joints of rats in the APE group (Figure 9(a)). A loss of safranin $\mathrm{O}$ and toluidine blue indicated severe cartilage destruction and bone erosion in rats from the model group. However, the damage was improved in the treated groups and the improvement was more prominent in the joints of rats from the APE group (Figures 9(b) and 9(c)). Collectively, 

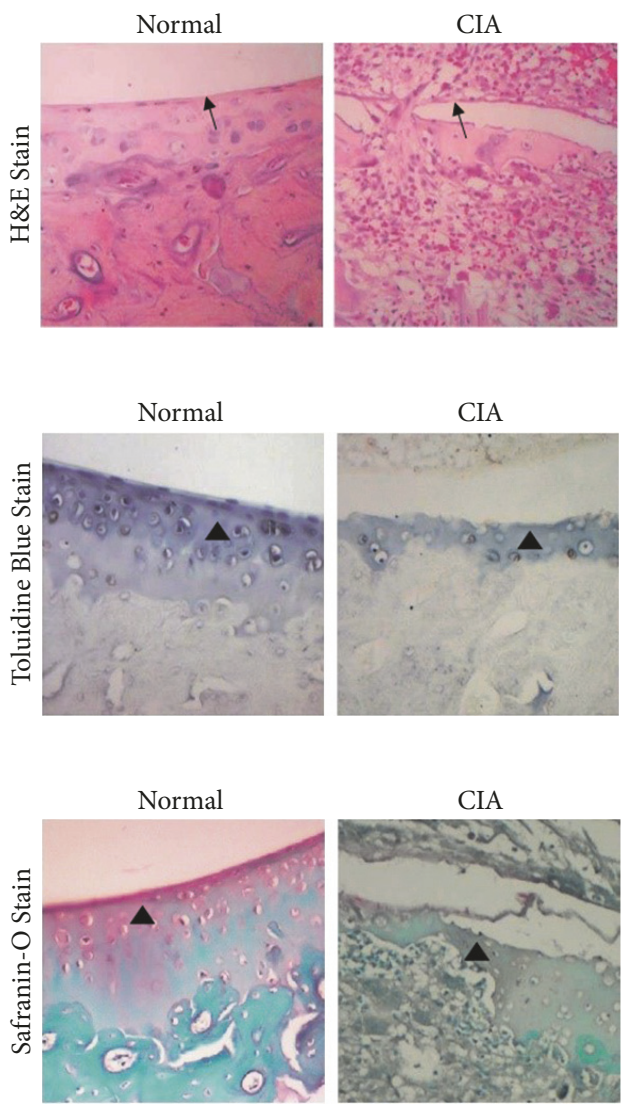

CIA

CIA

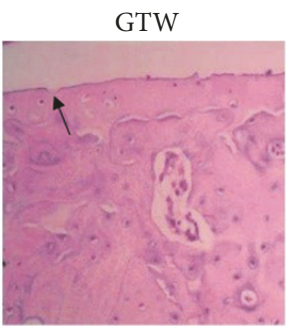

(a)

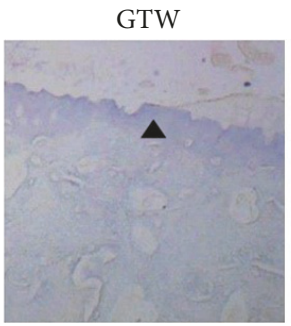

(b)

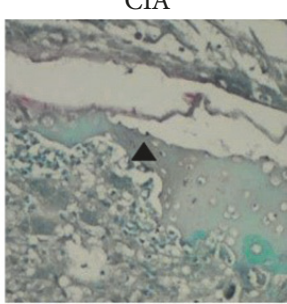

GTW

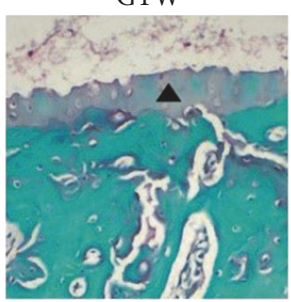

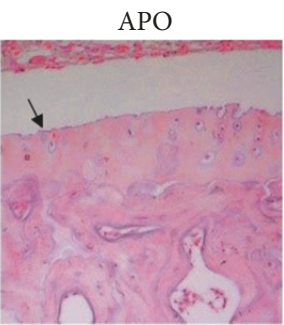

APO

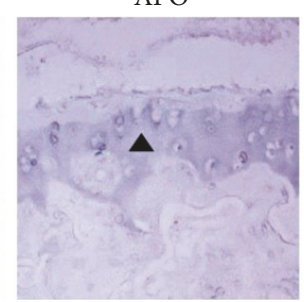

APO

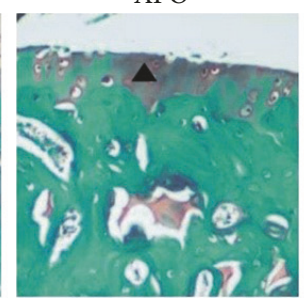

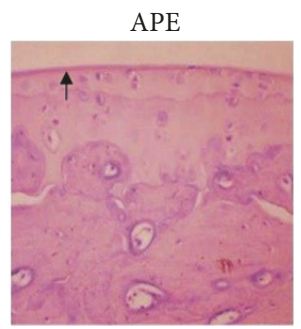

APE

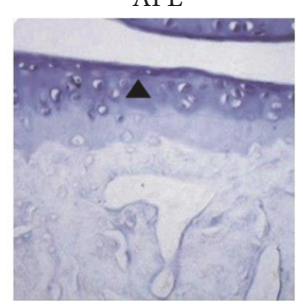

APE

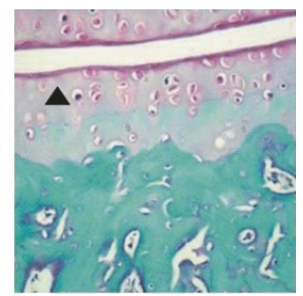

(c)

FIGURE 9: Representative images of joint tissues stained with $H \& E$, safranin $O$, and toluidine blue (original magnification, $\times 200$ ). (a) Images stained with $\mathrm{H} \& \mathrm{E}$ revealed that synovial hyperplasia, inflammatory cell infiltration, the vascular pannus formation, and cartilage destruction were inhibited in the treated groups, especially the APE group when compared with the model group. The arrows indicated synovium. (b, c) Images stained with safranin $\mathrm{O}$ and toluidine blue showed that cartilage destruction and bone erosion were ameliorated in the treated groups, especially the APE group when compared with the model group. The triangles indicated articular cartilage.

these results demonstrated that Agkistrodon peptides can effectively attenuate inflammation, cartilage destruction, and bone erosion caused by CIA.

\section{Discussion}

Proinflammatory cytokines such as TNF- $\alpha$, IL-1 $\beta$, and IL6 found in high concentrations in the synovial fluid and tissues of RA patients are crucial mediators of synovitis and subsequent erosive process of bone destruction. Macrophages release TNF- $\alpha$, IL- 6 , and IL- $1 \beta$ to directly or indirectly act on inflammatory cells, leading to the inhibition of synthesis and the promotion of degradation of CII and chondrocyte apoptosis and may cause irreversible cartilage destruction and bone damage $[2,28,29]$ (Figure 2). Alterations of proinflammatory cytokines have shown the potential for therapeutic intervention of RA [30, 31].

The Agkistrodon has long been used as a potent antiarthritic drug since ancient times [32]. A recent study carried out on CIA rats tested the optimal dosage of dried Agkistrodon for treatment of RA, yet functioning components within were not further discussed. In the present study, peptides were extracted from crude medicine of dried $\mathrm{Ag}$ - kistrodon and were further separated by ion-exchange chromatography (IEC), followed by MALDI-TOF/TOF mass spectrometry identification. Biological activity of the isolated peptides was tested. It was observed in RAW264.7 cells that LPS-stimulated TNF- $\alpha$, IL- $1 \beta$, IL- 6 , and NF- $\kappa$ B mRNA expressions were inhibited in a dose-dependent manner. The peptides' effects were then evaluated by in vivo animal model of RA. The APE-treating group compared to the arthritis model group without had obviously lower clinical arthritis indexes and serum anti-collagen type II IgG. It was interesting to observe that the APE-treating group compared to the APO group had lower paw swelling and clinical arthritis indexes, which might be attributed to longer digestion time of the APO powder. While time was spared on digestion of the hard powder to release beneficial peptide/protein components, the small peptides compound may survive the degradation and exert an effect without the digestion time [33]. The peptides' antiarthritic effects were further supported by the histological HE staining results, demonstrating reduced synovial hyperplasia, inflammatory cell infiltration, and cartilage destruction, as well as the immunohistochemical assay that showed decreased expressions of TNF- $\alpha$, IL- $1 \beta$, and IL- 6 in the rats' joints of the treating group. 
Deviation of inflammatory cytokine production/secretion has been associated with protection mediated by different peptide epitopes of the autoantigens including heat shock protein 65 , as well as collagen II $[34,35]$. These toleranceinducing peptides are believed to mediate suppressive effects by either directly neutralization of antigen-specific T cells or inducing cell populations that suppress the effector $\mathrm{T}$ cells $[36,37]$.

The mass spectrometer produced unique cleavage patterns of the peptides, which were then used to search for top matches within the database. It is interesting to note/notice that several fragments of the collagen from Ophiophagus hannah were recognized as matches, which strongly indicated the likelihood of existence of epitopes of the autoantigen. This might partially explain the inhibition of proinflammatory cytokines and the protection from bone destruction.

\section{Conclusion}

Previous study clarified the therapeutic benefits of the crude Agkistrodon powder, based on which we hypothesized peptides/proteins as vital components contained in the crude medicine. The hypothesis was confirmed in the present study by successful isolation of a small peptides compound, followed by demonstration of its better antiarthritic effect comparing the powder. The comparison implied potential of the small peptides as an equivalent therapy of the crude complex. Demonstration of the separation and beneficial effects of the compound though did not exclude the likelihood of potent peptides/proteins identified from the crude Agkistrodon in the near future by taking advantage of sophisticated chromatographic methods.

\section{Conflicts of Interest}

The authors declared that they have no conflicts of interest.

\section{Authors' Contributions}

Lijun Mei and Chen Lin contributed equally to this work and should be considered co-first authors. All authors reviewed the manuscript.

\section{Acknowledgments}

This study was supported by Zhejiang Provincial Natural Science Foundation of China (Grant no. LQ18H280002); National Basic Research Program of China (973 Program, Grant no. 2014CB543000); National Natural Science Foundation of China (81673857); Basic Research Program of Education Department of Zhejiang Province (Y201430952); the Science and Technology Planning Project of Zhejiang Province (no. 2016F81G2120035).

\section{References}

[1] M. Stenman, M. Ainola, L. Valmu et al., "Trypsin-2 degrades human type II collagen and is expressed and activated in mesenchymally transformed rheumatoid arthritis synovitis tissue," The American Journal of Pathology, vol. 167, no. 4, pp. 11191124, 2005.

[2] S. Mateen, A. Zafar, S. Moin, A. Q. Khan, and S. Zubair, "Understanding the role of cytokines in the pathogenesis of rheumatoid arthritis," Clinica Chimica Acta, vol. 455, pp. 161171, 2016.

[3] S. Siebert, A. Tsoukas, J. Robertson, and I. McInnes, "Cytokines as therapeutic targets in rheumatoid arthritis and other inflammatory diseases," Pharmacological Reviews, vol. 67, no. 2, pp. 280-309, 2015.

[4] B. D. Furman, D. S. Mangiapani, E. Zeitler et al., "Targeting pro-inflammatory cytokines following joint injury: acute intraarticular inhibition of interleukin-1 following knee injury prevents post-traumatic arthritis," Arthritis Research \& Therapy, vol. 16, no. 3, article R134, 2014.

[5] D. L. Scott, F. Wolfe, and T. W. J. Huizinga, "Rheumatoid arthritis," The Lancet, vol. 376, no. 9746, pp. 1094-1108, 2010.

[6] X. Kong, Y. Zhang, C. Liu et al., "Anti-angiogenic effect of triptolide in rheumatoid arthritis by targeting angiogenic cascade," PLoS ONE, vol. 8, no. 10, Article ID e77513, 2013.

[7] J. A. Singh, K. G. Saag, S. L. Bridges Jr. et al., "American College of Rheumatology Guideline for the Treatment of Rheumatoid Arthritis," Arthritis Rheumatol, vol. 68, no. 1, pp. 1-26, 2015.

[8] J. W. J. Bijlsma, P. M. J. Welsing, T. G. Woodworth et al., "Early rheumatoid arthritis treated with tocilizumab, methotrexate, or their combination (U-Act-Early): a multicentre, randomised, double-blind, double-dummy, strategy trial," The Lancet, vol. 388, no. 10042, pp. 343-355, 2016.

[9] D. D. Obiri, N. Osafo, P. G. Ayande, and A. O. Antwi, "Xylopia aethiopica (Annonaceae) fruit extract suppresses Freunds adjuvant-induced arthritis in Sprague-Dawley rats," Journal of Ethnopharmacology, vol. 152, no. 3, pp. 522-531, 2014.

[10] P. Zhang, J. Li, Y. Han, X. W. Yu, and L. Qin, "Traditional Chinese medicine in the treatment of rheumatoid arthritis: a general review," Rheumatology International, vol. 30, no. 6, pp. 713-718, 2010.

[11] D. J. Newman and G. M. Cragg, "Natural products as sources of new drugs over the 30 years from 1981 to 2010," Journal of Natural Products, vol. 75, no. 3, pp. 311-335, 2012.

[12] L. Dardevet, D. Rani, T. A. El Aziz et al., "Chlorotoxin: A helpful natural scorpion peptide to diagnose glioma and fight tumor invasion," Toxins, vol. 7, no. 4, pp. 1079-1101, 2015.

[13] Y.-H. Yang, R. Rajaiah, E. Ruoslahti, and K. D. Moudgil, "Peptides targeting inflamed synovial vasculature attenuate autoimmune arthritis," Proceedings of the National Acadamy of Sciences of the United States of America, vol. 108, no. 31, pp. 12857-12862, 2011.

[14] M. S. Wong, A. Tso, Ali. M. et al., "Novel T-cell inhibiting peptides delay the onset of Type 1 diabetes in non-obese diabetic mice," Diabetes and Metabolism, vol. 40, no. 3, pp. 229-234, 2014.

[15] A. Gomes, S. Ghosh, S. Ghosh et al., "Anti-osteoarthritic activity of Bungarus fasciatus venom fraction BF-F47 involving molecular markers in the rats," Toxicon, vol. 118, pp. 43-46, 2016.

[16] A. Gomes, P. Datta, T. Das, A. K. Biswas, and A. Gomes, "Anti arthritic and anti inflammatory activity of a cytotoxic protein NN-32 from Indian spectacle cobra (Naja naja) venom in male albino rats," Toxicon, vol. 90, pp. 106-110, 2014.

[17] Q. Zhu, J. Huang, S.-Z. Wang, Z.-H. Qin, and F. Lin, "Cobrotoxin extracted from Naja atra venom relieves arthritis symptoms 
through anti-inflammation and immunosuppression effects in rat arthritis model," Journal of Ethnopharmacology, vol. 194, pp. 1087-1095, 2016.

[18] K. L. Wong, R. N. S. Wong, L. Zhang et al., "Bioactive proteins and peptides isolated from Chinese medicines with pharmaceutical potential," Chinese Medicine, vol. 9, article 19, 2014.

[19] S. F. Darwish, W. M. El-Bakly, H. M. Arafa, and E. ElDemerdash, "Targeting TNF- $\alpha$ and NF- $\kappa$ B activation by bee venom: Role in suppressing adjuvant induced arthritis and methotrexate hepatotoxicity in rats," PLoS ONE, vol. 8, no. 11, Article ID e79284, 2013.

[20] J. Bao, Z.-J. Xie, L.-M. Chen, J. Sun, and Y.-S. Fan, "Effects of agkistrodon in different dosage forms on collagen-induced arthritis in rats," Chinese Journal of Integrative Medicine, vol. 22, no. 12, pp. 902-909, 2016.

[21] X. Tao, H. Schulze-Koops, L. Ma, J. Cai, Y. Mao, and P. E. Lipsky, "Effects of Tripterygium wilfordii Hook F extracts on induction of cyclooxygenase 2 activity and prostaglandin E2 production," Arthritis \& Rheumatology, vol. 41, no. 1, pp. 130-138, 1998.

[22] K. Maekawa, N. Yoshikawa, J. Du et al., “The molecular mechanism of inhibition of interleukin- $1 \beta$-induced cyclooxygenase- 2 expression in human synovial cells by Tripterygium wilfordii Hook F extract," Inflammation Research, vol. 48, no. 11, pp. 575$581,1999$.

[23] Y. Zhang, W. Xu, H. Li et al., "Therapeutic effects of total alkaloids of tripterygium wilfordii Hook f. on collagen-induced arthritis in rats," Journal of Ethnopharmacology, vol. 145, no. 3, pp. 699-705, 2013.

[24] X.-J. Li, Z.-Z. Jiang, and L.-Y. Zhang, "Triptolide: progress on research in pharmacodynamics and toxicology," Journal of Ethnopharmacology, vol. 155, no. 1, pp. 67-79, 2014.

[25] L. Bo, H. Yonghong, Z. Mingmin et al., "Effect of glycoside of tripterygium wilfordii hook.f on expression of receptor activator of nuclear factor- $\kappa$ b ligand and osteoprotegerin in joints of rat adjuvant induced arthritis," Herald of Medicine, vol. 5, no. 25, pp. 395-397, 2006.

[26] N. Liu, M. Yang, W. Luo et al., "Inhibitory effects of methotrexate and tripterygium glycosides on chemokine CCL5 production in synoviocytes from patients with rheumatoid arthritis," Journal of the Fourth Military Medical University, vol. 12, no. 27, pp. 1113-1115, 2006.

[27] J. Zhao, T. Liu, F. Xu, S. You, C. Li, and Z. Gu, "Anti-arthritic effects of total flavonoids from Juniperus sabina on complete freund's adjuvant induced arthritis in rats," Pharmacognosy Magazine, vol. 12, no. 47, pp. 178-183, 2016.

[28] Y. Ma and R. M. Pope, "The role of macrophages in rheumatoid arthritis," Current Pharmaceutical Design, vol. 11, no. 5, pp. 569580, 2005.

[29] I. B. McInnes, C. D. Buckley, and J. D. Isaacs, "Cytokines in rheumatoid arthritis-shaping the immunological landscape," Nature Reviews Rheumatology, vol. 12, no. 1, pp. 63-68, 2016.

[30] M. C. Genovese, M. Greenwald, C. Cho et al., "A phase II randomized study of subcutaneous ixekizumab, an antiinterleukin-17 monoclonal antibody, in rheumatoid arthritis patients who were naive to biologic agents or had an inadequate response to tumor necrosis factor inhibitors," Arthritis \& Rheumatology, vol. 66, no. 7, pp. 1693-1704, 2014.

[31] J. Alam, I. Jantan, and S. N. A. Bukhari, "Rheumatoid arthritis: Recent advances on its etiology, role of cytokines and pharmacotherapy," Biomedicine \& Pharmacotherapy, vol. 92, pp. 615633, 2017.
[32] Q. Cai, J.-M. Meng, and X.-H. Han, "Clinical study on effect of Agkistrodon antithrombogenase in auxiliary treatment of rheumatoid arthritis," Zhongguo Zhong Xi Yi Jie He Za Zhi, vol. 22, no. 3, pp. 166-168, 2002.

[33] F. Y. Yang, T. M. Fu, L. W. Guo et al., "Degradation of earthworm extracts prepared by wet superfine grinding in simulated gastrointestinal environment," Yao Xue Xue Bao, vol. 47, no. 1, pp. 110-115, 2012.

[34] R. A. Benson, J. M. Brewer, and A. M. Platt, "Mechanisms of autoimmunity in human diseases: a critical review of current dogma," Current Opinion in Rheumatology, vol. 26, no. 2, pp. 197-203, 2014.

[35] S.-C. Law, H. Benham, H. H. Reid, J. Rossjohn, and R. Thomas, "Identification of self-antigen-specific T cells reflecting loss of tolerance in autoimmune disease underpins preventative immunotherapeutic strategies in rheumatoid arthritis," Rheumatic Disease Clinics of North America, vol. 40, no. 4, pp. 735-752, 2014.

[36] M. I. Koenders and W. B. van den Berg, "Novel therapeutic targets in rheumatoid arthritis," Trends in Pharmacological Sciences, vol. 36, no. 4, pp. 189-195, 2015.

[37] M. Miyara, Y. Ito, and S. Sakaguchi, "TREG-cell therapies for autoimmune rheumatic diseases," Nature Reviews Rheumatology, vol. 10, no. 9, pp. 543-551, 2014. 


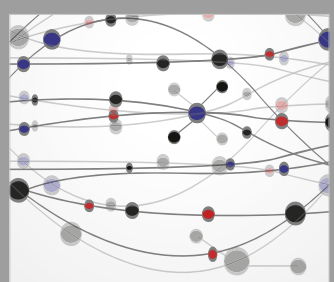

The Scientific World Journal
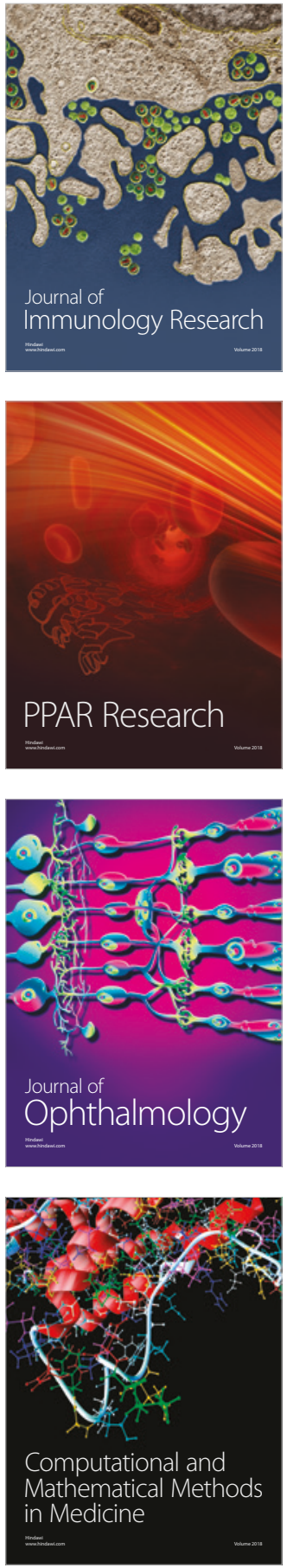

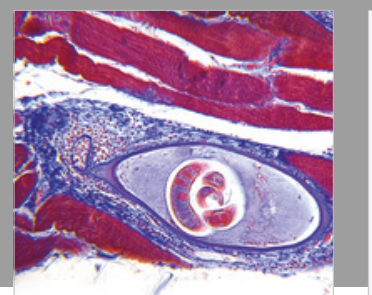

Gastroenterology Research and Practice

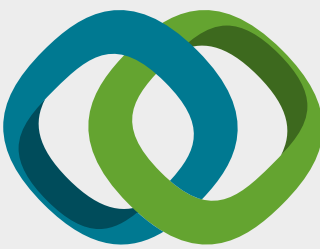

\section{Hindawi}

Submit your manuscripts at

www.hindawi.com
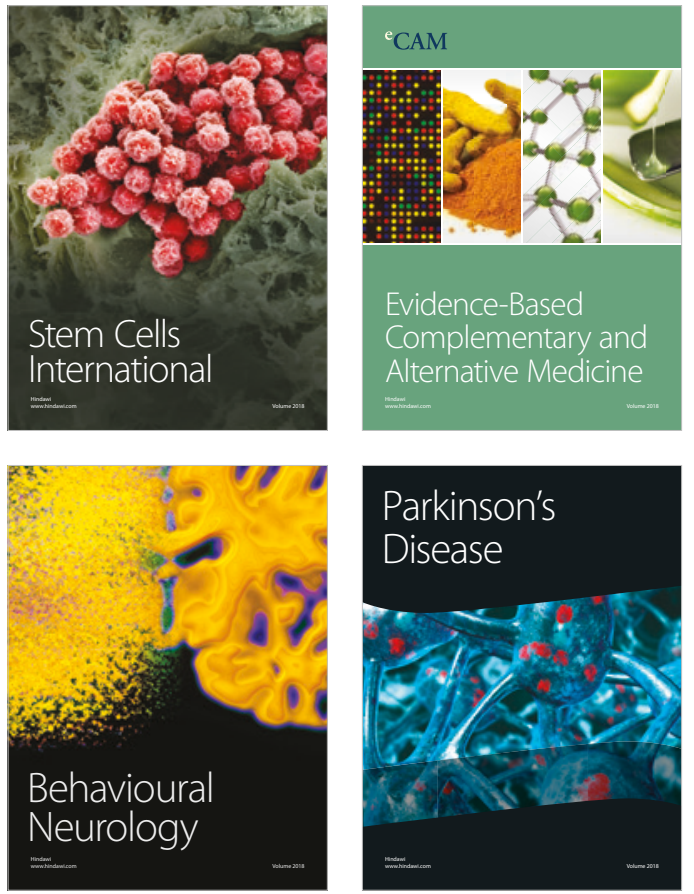

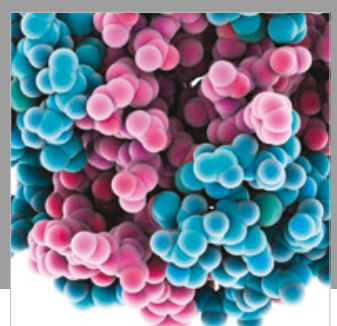

ournal of

Diabetes Research

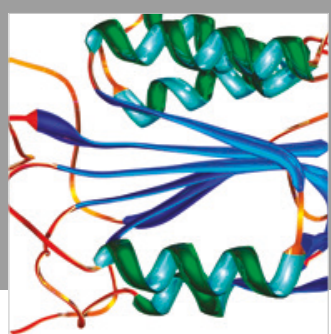

Disease Markers
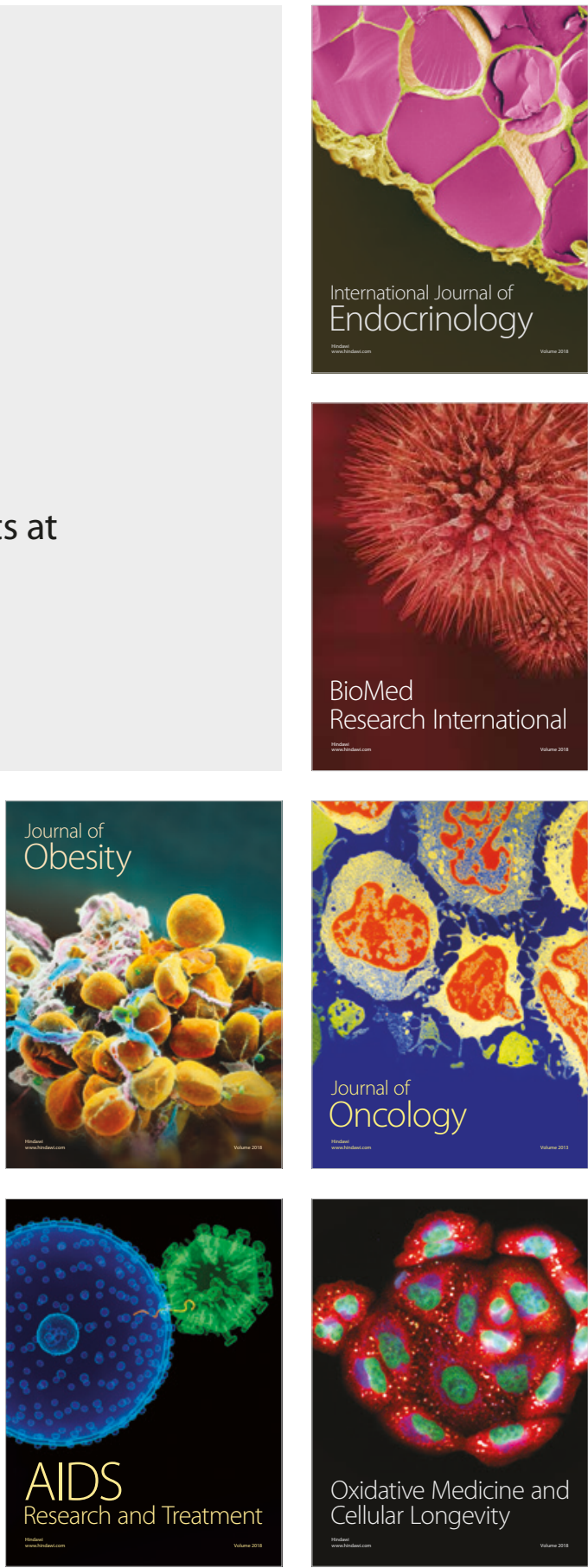